\title{
Harnessing the therapeutic potential of myogenic stem cells
}

\author{
Jason D. White* \& Miranda D. Grounds \\ School of Anatomy and Human Biology, The University of Western Australia, Crawley, Perth, Western Australia, \\ Australia \\ (*Author for correspondence; E-mail: jwhite@anhb.uwa.edu.au)
}

Key words: cell transplantation, muscular dystrophy, skeletal muscle, stem cell

\begin{abstract}
The potential clinical use of stem cells for cell transplantation therapies to replace defective genes in myopathies is an area of intense investigation. Precursor cells derived from non-muscle tissue with myogenic potential have been identified in many tissues, including bone marrow and dermis, although the status of these putative stem cells requires clarification. The incorporation of circulating bone-marrow derived stem cells into regenerating adult skeletal muscle has been demonstrated in mice but the contribution of donor cells is so minimal that it would appear clinically irrelevant at this stage. The possibility of a true stem cell subpopulation within skeletal muscle that replenishes the satellite cells (conventional muscle precursors on the surface of myofibres) is also very attractive as a superior source of myoblasts for muscle construction. A full understanding of the intrinsic factors (i.e. gene expression within the stem cell) and extrinsic factors (i.e. signals from the external environment) which control the commitment of stem cells to the myogenic lineage, and the conditions which favour stem cell expansion in vivo is required before stem cells can be seriously considered for clinical cell therapy.
\end{abstract}

\section{Introduction}

Skeletal muscle has an excellent ability to regenerate and adapt to physiological demands such as growth, training and injury. Until recently the re-building of damaged post-natal skeletal muscle has been attributed largely to a population of precursor cells, widely referred to as satellite cells, which lie outside the sarcolemma but beneath the basement membrane of muscle fibres. In response to trauma, satellite cells become activated, proliferate, differentiate and eventually fuse into myotubes that mature into myofibers (Grounds, 1991). The process of skeletal muscle regeneration is influenced by a number of factors including the nature of the injury, growth factors and the extracellular matrix.

The natural biology of skeletal muscle regeneration, which depends on fusion of myoblasts into multinucleated syncitial muscle fibres, is the basis for cell-based gene replacement therapies for lethal muscle diseases such as Duchenne Muscular Dys- trophy (DMD). Boys with DMD have defective dystrophin protein and the aim of Myoblast Transfer Therapy (MTT) is to alleviate the myopathy by introducing dystrophin into diseased muscles by implanting normal donor myoblasts. The source of such myoblasts, from embryonic or adult non-muscle stem cells, or from conventional satellite cells, is the topic of this review.

There is indisputable evidence that non-muscle stem cells can have myogenic potential. To date, much research has focused on trying to identify and characterize these cells based mainly on fluorescent activated cell sorting (FACS) analysis of cell surface markers. Only now are researchers starting to evaluate key questions related to the microenvironment, including extracellular matrix and soluble factors, that will maximise the incorporation of implanted (stem cell or other) myogenic cells. The development of clinical cell transplantation therapies based on stem cells will likely depend on the design of approaches that consider both the intrinsic factors (gene expression within 
the stem cell) and extrinsic factors (interaction with the local environment) that control cell fate and the effective recruitment of stem cells into the myogenic lineage.

One important aspect that does not seem to have been widely considered is the stem cell status of the myogenic cell that is derived by conversion of the non-myogenic stem cell (e.g. HSC). Is this newly formed myogenic cell actually a stem cell? If the answer is 'NO', then this requires that the original non-myogenic stem cell must repeatedly undergo conversion into such myoblasts, and this in turn depends upon continual exposure to appropriate conditions (Figure 1). The alternative scenario is that the initial non-myogenic stem cell is indeed converted into a true myogenic stem cell with a great capacity for selfrenewal: this is far more attractive as only a single initial 'conversion' event (from the non-myogenic stem cell) is required for the subsequent efficient generation of many myoblasts (see Figure 1). The two major properties of stem cells are plasticity and self renewal with an extended capacity for cell proliferation. Many of the recent striking observations regarding stem cells seem to reflect plasticity: whether they also embody the key feature of sustained self renewal has often not been addressed (especially in vivo).

There is now increasing debate regarding the true nature of apparent plasticity (Frisen, 2002). A totally new explanation has recently emerged for observations that were presumed to result from conversion (plasticity, de-differentiation, transdifferentiation or de-differentiation) and genetic reprogramming of an individual cell. Instead, fusion between a differentiated cell and an embryonic stem (ES) cell in tissue culture to form a hybrid polyploid cell, results in adoption of a stem cell phenotype by the previously differentiated cell (Terada et al., 2002; Ying et al., 2002). In the case of a mononucleated cell such a fused cell is tetraploid: however, the ability of a single nucleus to discard surplus chromosomes may make such polyploid nuclei hard to detect. Furthermore, it is not clear whether nuclear fusion (to form a heterokaryon) after such cell fusion is inevitable, instead perhaps the two individual nuclei might co-exist in the syncitium of a cell that is normally multinucleated (as for a muscle fibre). This is a radically different interpretation of events and it is not clear how widespread such fusion might be to account for many of the recent observations in the literature.

\section{What is the best source of cells for transplantation based therapies?}

Traditionally the satellite cell, defined mainly by its geographical location, has been considered the classical source of precursor cells (myoblasts) for the repair of injured post-natal skeletal muscle (Grounds et al., 2002). Therefore, when cells were extracted from skeletal muscle and a primary culture established in vitro it was assumed that the cultured muscle precursors were derived only from the satellite cells (Lee et al., 2000). Yet clearly many other cell types are present within the original skeletal muscle tissue. More recently this perception of a central role for satellite cells has been challenged by identification of multiple populations of 'stem cells' capable of entering the myogenic lineage. Recent knowledge and progress in muscle stem cell and satellite cell biology have been extensively reviewed recently (Goldring et al., 2002c; Grounds et al., 2002; Zammit and Beauchamp, 2001) and will not be dealt with in depth here.

The suggestion has been made that the efficiency of cell transplantation into muscle might be improved by using stem cells derived from non-muscle sources. Stem cells appear to have four potential advantages compared with satellite cells. One key property of stem cells is the capacity for self renewal and this exaggerated ability for proliferation represents a potent capacity for production of many donor cells.

The second property of stem cells is plasticity, which means that non-muscle cells can be converted into the myogenic lineage and used as a source of donor myoblasts. This is particularly attractive for autologous MTT (where the patient's own cells are used) as this would avoid long term immunological problems encountered with foreign donor cells. For autologous MTT, myogenic stem cells from the patient would be harvested, genetically corrected (outside the body) and then re-implanted back into the patient to correct the gene defect. In DMD where the compromised dystrophic muscle is a poor source of muscle cells, autologous stem cells derived from other tissues such as the patient's dermis or bone-marrow, represent an alternative source of cells that can be conveniently converted into the myogenic lineage.

The use of bone-marrow stem cells as a source of myoblasts represents the ideal systemic delivery system to all muscles of the body. In theory, bone-marrow derived stem cells would be a permanent source of circulating precursors that would convert to myoblasts in 


\section{Non-myogenic \\ Stem Cell}

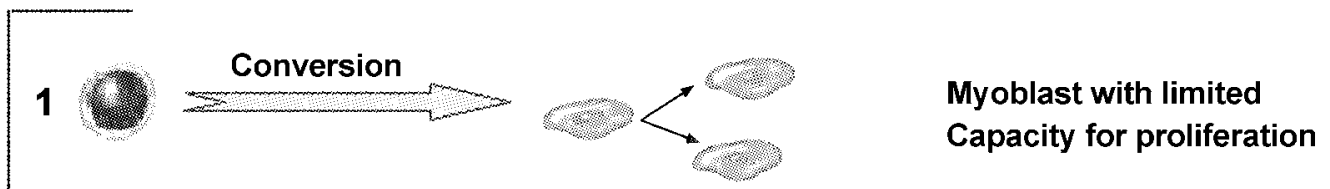

\section{Asymmetric Cell division}

2
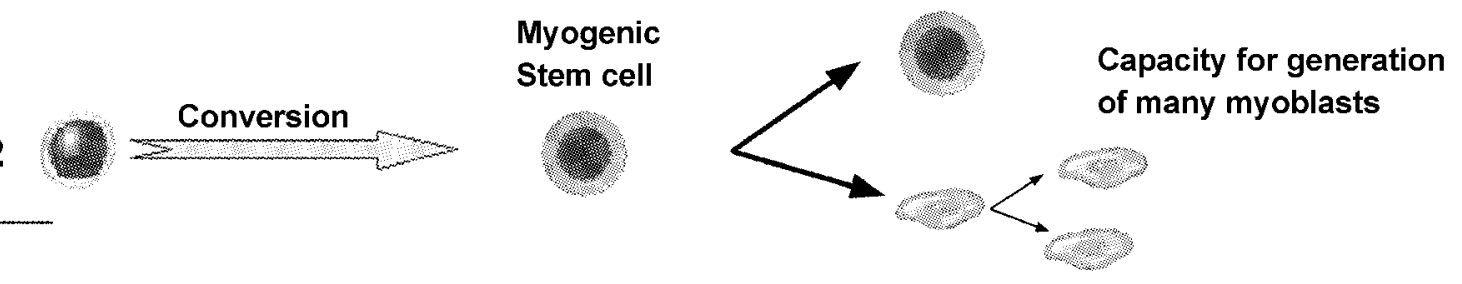

Fusion of 2 cells
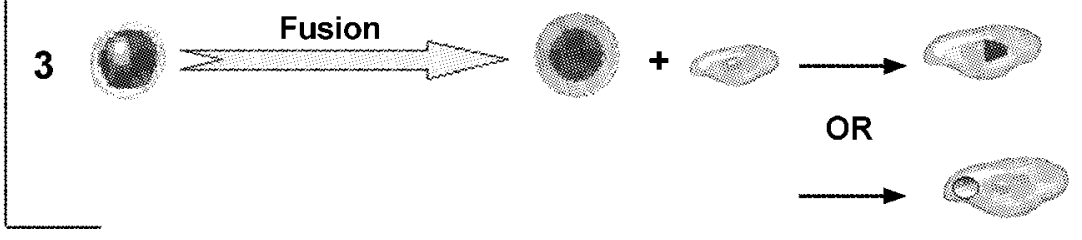

\section{Fused stem cell/myoblast with Hybrid (tetraploid) nucleus.}

\section{Hybrid stem cell/myoblast with two nuclei}

Figure 1. Three scenarios for the contribution of non-myogenic stem cells to the myogenic lineage. When a non-muscle stem cell converts to the myogenic lineage there are several different outcomes. 1. Direct conversion of the non-myogenic stem cell to a committed myoblast, with a limited capacity for replication; this scenario does not produce a committed myogenic stem cell with the capacity for self-renewal. 2. Conversion of the non-myogenic stem cell to a committed myogenic stem cell. Asymmetric division of the new myogenic stem cell gives rise to 2 daughter cells, one a new myogenic stem cell (self-renewal) and the other a myoblast (again with a limited capacity for proliferation). 3. Direct cell fusion, the non-myogenic stem cell directly fuses with a muscle cell (myoblast, myotube or myofibre) creating a hybrid cell; The two nuclei may fuse to form one tetraploid nucleus or remain as separate entities within the cytoplasm. The proliferative capacity of these cells is unclear.

muscle tissue as required, a highly desirable clinical scenario that is relatively non-invasive.

Immune privilege has also been claimed for stem cells (see below). If true this would be a huge bonus. However, this situation requires more detailed investigation. Even if a foreign stem cell is exempt from the initial host immune response, it seems logical to conclude that once a stem cell has revealed its full lineage potential and differentiated into a mature cell type, this would be equivalent to the same differentiated cell derived from a conventional myoblast and be considered as foreign by the host, unless the stem cell somehow induced host tolerance. Such issues require clarification.

\section{Problems with immune response}

Immune problems must always be considered when dealing with clinical cell transplantation. It has long been recognized that transplantation of foreign donor cells into embryos may avoid long-term problems of immune rejection since the donor cells are recognized as 'self' by the immature immune system of the developing host (Brent et al., 1976). However, in utero MTT is not the most likely scenario. In contrast, the same donor cell implanted into a mature host will be recognized as foreign and rejected within a few weeks: this applies even to newborns as the immune system is relatively mature. Since clinical MTT would probably be applied to children, a significant adverse host immune response to foreign donor cells needs to be considered. 
An additional unexpected problem involving a very rapid adverse host immune response has been identified from experimental studies in mice. Intramuscular injection of cultured (congenic) donor myoblasts in classical MTT results in massive and rapid death of donor myoblasts, with over $80 \%$ dead within the first hour after injection (reviewed in Beauchamp et al., 1999; Skuk and Tremblay, 2000; Smythe et al., 2000, 2001). This rapid myoblast death appears to be due to exposure to tissue culture conditions (Smythe and Grounds, 2000) that alter the myoblasts so that, when transferred in vivo, they provoke an acute adverse host immune response. It is noted that when equivalent intact donor muscles are implanted directly, without exposure to cell isolation and tissue culture, there is no adverse immune response and grafts show excellent survival for up to a year (Fan et al., 1996; Smythe and Grounds, 2000). Host natural killer (NK) cells appear to play a particularly important role in this rapid death of cultured donor myoblasts (Hodgetts et al., 2000).

The extent to which such immune problems also occur with intramuscular transplantation of donor stem cells or with delivery of donor (stem or other) cells via the circulation is unclear (Grounds et al., 2002). One of the first suggestions that stem cells might evade the immune response came from observations that a small population of donor myoblasts survived MTT and subsequently proliferated (in irradiated muscle), implying that this rare surviving population might represent myogenic stem cells (Beauchamp et al., 1999). Subsequent MTT studies using late preplate myogenic stem cells also claim immune privilege for these myogenic stem cells (Qu et al., 1998). The report that mesenchymal stem cells from adult human bone marrow are exempt from rejection after xenotransplantation into sheep (in contrast to other stem cells) is intriguing (Liechty et al., 2000). These donor MSC cells were detected in many tissues (although their survival was not quantitated), and such unexpected immune tolerance has major implications for clinical cell therapies and requires further investigation.

\section{Comparison of embryonic and postnatal stem cell potential}

Several key questions need to be addressed regarding the ideal source of stem cells. Are there significant differences between different types of stem cells de- rived from embryonic, foetal, neonatal or adult tissues (Figure 2) with respect to their capacity to give rise to fully functional myogenic cells? Which might be the most suitable for clinical applications, bearing in mind ethical and other considerations?

Most applications in clinical situations will involve repair of post-natal or mature skeletal muscles by such stem cells. Almost all research in the muscle stem cell field has focused on the delivery of adult stem cells into adult tissues. One major problem is that many (embryonic and adult) stem cells unfortunately show limited plasticity and minimal contribution to tissue formation in mature host tissues, in marked contrast to the striking plasticity in embryonic/developing tissues. This important difference was emphasized by the formation of many tissues in embryos that were derived from adult bone-marrow mesenchymal stem cells transplanted into blastocysts, but the same adult stem cells barely had any effect when transplanted into adults (Jiang et al., 2002). Such observations emphasise the crucial importance of the environment that the stem cells find themselves in. This is also highlighted by the finding that the myogenic program of embryonic stem cells was retarded in mice that lack beta1-integrin (Czyz and Wobus, 2001; Goodell et al., 1996; Rohwedel et al., 1998), which mediate cell-cell and cell-matrix interactions. That cell fate is determined by a balance between intrinsic and extrinsic factors is elegantly discussed with respect to stem cells and cancer, where the intrinsic tumourogenic potential of a cell line is silent in a young liver but is manifested in the microenvironment of an old liver (Presnell et al., 2002).

The following discussion explores different types of stem cells and their potential use in the human situation.

\section{Are embryonic stem cells a potential source of muscle precursors for transplantation?}

The classical pluripotential embryonic stem (ES) cell is derived from the inner cell mass of blastocysts (before implantation). Other cells may be derived from the embryo after implantation and when taken from the developing gonadal ridge, these are called primordial germ cells (Figure 2). ES cells are capable of differentiating into a variety of cell types in vitro and into somatic and germ-line cells in vivo. There is a considerable body of work describing the differentiation of ES cells, as embryoid bodies, down the myogenic 


\title{
Stem cells can be derived from tissues throughout development
}

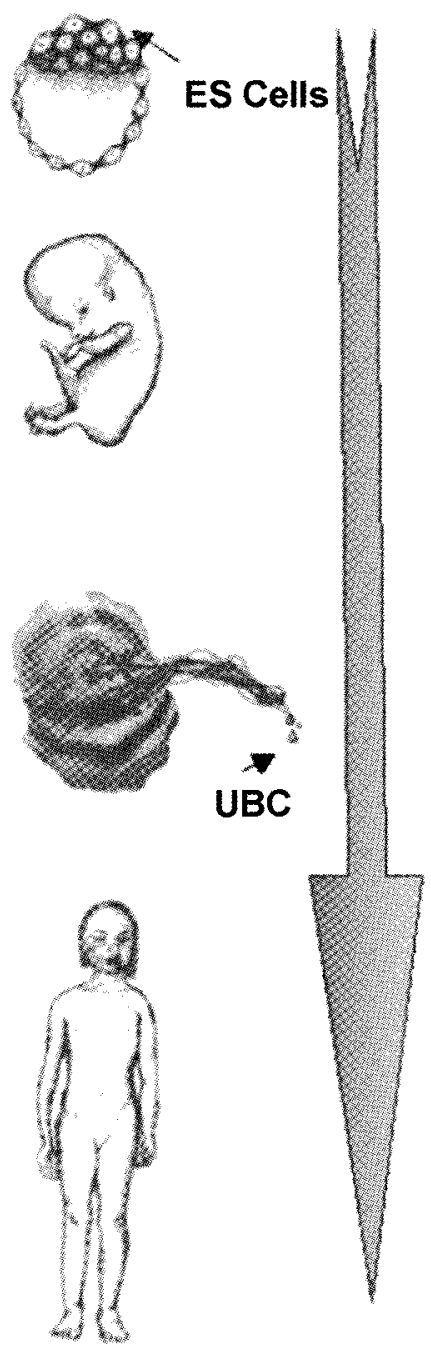

\author{
Blastocyst \\ ES cells \\ Embryo/Fetal \\ Germ cells \\ Fetal tissues
}

\author{
Umbilical Cord \\ Umbilical cord blood (UCB) \\ Supporting tissues
}

\section{Post-Natal Tissues}

\section{Skeletal muscle derived stem cells for satellite cells}

\section{Non-muscle tissue Bone marrow, interstitial connective tissue, dermis, other.}

Figure 2. Developmental sources of stem cells. Stem cells with proven ability to contribute to the myogenic lineage have been isolated from tissues at various stages of development. This ranges from totipotential ES cells from the blastocyst before implantation, to embryonic tissues, cells from the umbilical cord (both blood and supporting tissues), and finally to various tissues from neonates to adults including skeletal muscle, dermis and bone marrow.

lineage and the in vitro studies indicate that this process recapitulates the in vivo process of myogenesis (Rohwedel et al., 1994). Such myogenic conversion of ES cells in vitro occurs under the influence of various factors especially methylating agents such as DMSO, and acetylation of histones appears to play a big role in skeletal myogenesis (Iezzi et al., 2002). Stem cells can be obtained from blastocysts containing either only the male alleles-androgenic (Mann and Stewart, 1991) or only the female alleles-parthenogenic (Allen et al., 1994). The analysis of tumours formed after sub- cutaneous injection of adrogenic ES cells (Mann et al., 1990) and in vitro differentiation assays (McKarney et al., 1997) show that these paternally-derived cells have an increased propensity to enter the myogenic lineage. This phenomenon has been directly associated with the expression of insulin-like growth factor II (Prelle et al., 2000).

Clearly ES cells can give rise to many cell types in culture and can be transplanted into other blastocysts where they can contribute to formation of many tissues in vivo. Many studies on ES cells have been based on 
the use of mouse tissue and it is important to consider that there may be critical differences between the behaviors of ES cells derived from mice and humans (Kehat et al., 2001). While human ES cells do not respond favourably to conditions developed for growing mouse cells in culture, optimization of in vitro conditions for human ES cells may well overcome this problem. There is clearly intense interest in investigating the equivalent capacity of human ES cells.

As already mentioned, fusion between an embryonic stem (ES) cell and a differentiated cell, can result in adoption of the stem cell phenotype presenting an alternative explanation of plasticity (Terada et al., 2002; Ying et al., 2002). One study showed that mouse bone-marrow stem cells (labeled with green fluorescent protein: GFP) can spontaneously fuse with ES cells and then behave like ES cells in culture although these hybrid cells did not generate chimaeric mice. Similarly, it appears that ES cells can be generated from neural cells, as neural cells changed their potency after spontaneous fusion with ES cells in tissue culture (Ying et al., 2002) to become pluripotent: these hybrid polyploid mononucleated cells were also able to form many tissues in vivo in chimaeric mice. Whether this spontaneous fusion is a feature of ES cells only, or can also occur with adult stem cells has not yet been investigated.

\section{Stem cells from developing embryos and fetuses}

The use of foetal or neonatal human tissue raises many serious ethical issues of a different nature to those related to harvesting human ES cells from blastocysts prior to implantation. Cells harvested from tissues of developing embryos generally show far more replicative capacity and plasticity than the equivalent tissue derived from more mature animals. Fascinating observations have shown that stem cells (called mesoangioblasts) derived from the dorsal aorta of mouse embryos have a remarkable capacity to form skeletal muscle both in vitro and in vivo (Minasi et al., 2002). This has led to the proposal that endothelial cells (or some other cells, perhaps pericytes, closely associated with capillary growth) may have the capacity to form new muscle and that this might also occur during normal revaascularisation of regenerating adult muscle tissue. However, while such meso-angioblast stem cells are readily obtained from embryonic and foetal blood vessels, this capacity appears to be rapidly lost after birth (Condorelli et al., 2001). This situ- ation indicates great plasticity of cells derived from embryonic and foetal tissues with restriction of stem cell capacity during maturation.

\section{Can umbilical cord blood cells be used as a source of myogenic cells?}

The umbilical cord represents a readily available, convenient (non-invasive) source of young stem cells with few ethical problems. The unbilical cord contains both unbilical cord blood (UCB) stem cells (Lewis and Verfaillie, 2000) and structural tissue that may have some stem cell properties; most attention has focused on the former and the banking of human cord blood for future autologous use is an expanding business. The presence of haematopoietic stem cells (HSC) is well documented in UCB (Rubinstein et al., 1995; Wyrsch et al., 1999). The relationship between bone-marrow derived HSC, endothelial stem cells (ES cells) and also mesenchymal stem cells (MSC) is complex (Jiang et al., 2002; Reyes et al., 2002). Throughout life, HSC and ES cells circulate in the blood. In contrast, in mature animals MSC probably remain in the bone marrow stroma although the extent to which MSC might circulate during development is unclear. The presence of MSC in UCB has been described (Campagnoli et al., 2001; Erices et al., 2000). The time of gestation, method of UCB isolation and subsequent culture conditions used, can dramatically affect the yield of MSC from UCB (Mareschi et al., 2001). The MSC from UCB have been shown to differentiate down the osteogenic, adipogenic and chondrogenic lineages (Campagnoli et al., 2001; Erices et al., 2000): no mention is made of any attempt to generate skeletal muscle cells from these cultures. The myogenic ability of UCB cells (either HSC, ES cells or MSC) requires in depth investigation as these remain an ethically acceptable and promising source of early stem cells for clinical purposes.

\section{Adult muscle derived stem cells}

Stem cells are easily identified in tissues that display a high rate of cell turnover in the course of normal tissue homeostasis, such as bone marrow, skin and the gut. Other stem cell compartments are difficult to isolate, especially where they exist in small numbers and may only be become activated after injury. Post-natal skeletal muscle has an excellent ability 
for regeneration and two different populations of putative stem cells have reportedly been derived from muscle: these are referred to as (i) side population (SP) and, (ii) late pre-plated 'muscle derived stem cells'. Both of these stem cell populations have been used in transplantation experiments.

\section{Side Population (SP) cells from muscle}

Side-population (SP) cells appear on FACS plots as a small population of cells off to the side of the main cell population (as the name suggests); these cells were originally identified as primitive HSC that eliminated the vital dye Hoechst 33342 via a multi-drug resistance MDR-like pump (Goodell et al., 1996). A similar SP of cells, with the same ability to eliminate Hoechst 33342, has been identified in cells extracted from adult mouse skeletal muscle. These skeletal muscle SP cells express several cell surface markers associated with HSC including CD34, c-kit, CD43 and CD45 (Gussoni et al., 1999), 80\% of muscle SP cells express Sca1 (Gussoni et al., 1999; Jackson et al., 1999) and discrepancies in the relative proportions of each of these markers have been reported (Gussoni et al., 1999; Jackson et al., 1999). The initial proposal that these SP cells were derived from satellite cells generated much excitement. It is noted that enzymatic digestion of skeletal muscle tissue extracts satellite cells along with many cells types including fibroblasts, macrophages, endothelial and other resident interstitial connective cells, plus circulating bone-marrow derived cells. It now appears that the muscle SP population extracted from skeletal muscle is derived from cells other than satellite cells, and is actually haematopoietic in origin (Asakura et al., 2002; Geiger et al., 2002; McKinney-Freeman et al., 2002).

It has also been shown that the muscle forming capacity of the muscle-derived SP (of HSC) depends on contact with committed muscle precursors. Thus, when injected directly into skeletal muscles in vivo the muscle-derived SP cells can effectively form muscle, but they shows a poor ability to enter the myogenic lineage in vitro and will only do so when co-cultured with primary myoblasts (Asakura et al., 2002). These observations emphasise the central importance of cellcell contact for such lineage conversion. Furthermore, they raise the possibility that this lineage conversion might actually be the result of fusion between SP cells and muscle cells (as discussed above).

\section{Late pre-plate Muscle Derived Stem Cells (MDSC)}

There is recent evidence that a subpopulation of satellite cells with stem cell properties may exist (Zammit and Beauchamp, 2001). Of particular interest are putative muscle derived stem cells (MDSC) isolated using serial platings, where the stem cells appear to have a reluctance to attach to the culture dish and are only harvested after many pre-platings that remove other cells (Qu et al., 1998). This technique when applied to cells extracted from mouse skeletal muscle, passages unattached floating cells into new culture flasks repeatedly over a 6 day period. After 6 such preplatings (PP6) the cultures are enriched for small cells; and clones derived from these cultures reportedly have 'stem cell' like characteristics (Lee et al., 2000; Qu et al., 1998). The true nature of these pre-plated cells remains to be clarified. Studies using these cells report a remarkable proliferative capacity and indicate that these PP6 cells after MTT are incorporated with greater efficiency into new muscle than conventional myoblasts. These MDSC appear to a superior source of myoblasts for MTT. It seems essential to quantitate the initial survival of these MDSC and compare this with their long-term survival and expansion of the cell population in vivo. Mouse muscle cells readily immortalize (due to high expression of telomerase) and form cell lines (Wright and Shay, 2002), yet this has not been reported with human muscle cells. It is therefore crucial to test whether an equivalent population of PP6 stem cells with such a superior capacity for cell proliferation can be extracted from human tissue, since clearly this would be required for any clinical use of these promising myogenic cells.

There are conflicting reports about the relative survival of pre-plated cells after direct intra-muscular injection. In 1998, Qu and colleagues reported enhanced survival of MDSC after injection into $\mathrm{mdx}$ muscle compared to primary myoblasts derived from isolated muscle fibres. In contrast, a recent study by Mueller et al. (2002) reported little difference in the number of dystrophin positive fibres after injection of PP6 MDSCs into the EDL muscle of mdx mice, a mouse model of muscular dystrophy. This study reported 25\% dystrophin positive fibres by 9 weeks after injection, which was not significantly different from the use of conventional myoblasts. 


\section{Non-muscle sources of myoblasts}

Stem cell populations with myogenic potential have long been recognized and described in many nonmuscle developing and mature tissues (Grounds et al., 2002). Only the skeletal muscle precursors derived from bone marrow, interstitial connective tissue and dermal fibroblasts are discussed below.

\section{Bone marrow}

The microenvironment of the hematopoietic cells within the bone-marrow is comprised of stromal cells which are a diverse population consisting of fibroblasts, smooth muscle cells, endothelial cells and others. These cells not only provide a scaffold to the developing stem and progenitor cells, but also produce extracellular matrix components and soluble proteins. Within the stromal cell population are MSC which are capable of self-renewal, as well as differentiation into many 'mesenchymal-derived' tissues. The common features among the cells referred to by different investigators as MSC is that they grow as adherent cells in culture and have the capacity to differentiate into osteoblasts, chondroblasts and adipocytes when exposed to the appropriate stimuli in vitro and vivo (Pereira et al., 1995; Pittenger et al., 1999; Prockop, 1997). It appears that MSC may also be present in the circulation, at least during development, as was discussed earlier for umbilical cord blood.

Human post-natal marrow MSC can form skeletal muscle (Zammit and Beauchamp, 2001) and can also give rise to endothelial cells (Reyes and Verfaillie, 2001) and other cell types and they appear to be closely related to pericytes in the vasculature (Bianco et al., 2001). In 1995, Wakitani et al. (1995) showed that stem cells from rat bone marrow have the ability to form myotubes when cultured in the presence of 5azacytidine and transplantation of bone marrow stem cells into the muscles of mdx mice induced the formation of dystrophin positive fibres (Saito et al., 1995). When total bone-marrow is used as a source of cells for such conversion studies, it is often unclear what the precise cell of origin of the cell is (i.e. HSC, ES cells, MSC). In the last 4 years many bone-marrow replacement studies have shown incorporation of donor derived bone marrow cells into the muscles of irradiated hosts (reviewed in Cossu and Mavilio, 2000). The level of donor cell incorporation, however, was always extremely low never exceeding $1 \%$ in accordance with very early experiments (Grounds, 1983; Grounds et al., 2002). That such rare contributions to new muscle have little therapeutic promise was demonstrated by analysis of dystrophic muscle from a boy with DMD who had received a normal bone-marrow transplant 13 years prior to analysis (Gussoni et al., 2002).

Good cell markers are required for such transplantation studies and GFP is a particular sensitive marker. The myogenic potential in vivo of bone marrow and fetal liver cells derived from donor mice that express GFP was recently reported by Fukada et al. (2002). Transfer of both types of cells into irradiated mdx hosts resulted in many GFP positive within skeletal muscle and more importantly increased dystrophin expression. Interestingly GFP positive cells were noted beneath the basal lamina implying contribution of the donor cells to satellite cell population. This is a similar finding to previous studies, which report localization of donor cells to a satellite cell position (Gussoni et al., 1999; Lee et al., 2000). However, it is important to note that this effect in the GFP study (Fukada et al., 2002) was relatively transient as only low levels of incorporation persisted out to 12 weeks.

Rigorous experiments used a single HSC labeled with GFP to very effectively reconstitute peripheral blood leukocytes in lethally irradiated mice (Wagers et al., 2002) and also to study GFP chimaerism in parabiotic mice. These studies with clonal HSCs found almost no evidence that the GFP labeled HSC contributed to non-haematopoetic tissues (including brain, kidney, gut, liver and muscle) in adult mice. It was concluded that 'transdifferentiation' of circulating HSCs and/or their progeny is an extremely rare event (if it occurs at all). These data endorse the extremely low contribution of bone-marrow derived cells to skeletal muscle formation in adults, as described by others.

\section{Cells from within interstitial connective tissues}

While MSC are found in the stroma of bone-marrow, the term MSC is also used to describe stem cells that can be isolated from a variety of adult tissues especially those with high connective tissue components. There is a large body of in vitro work by Young and colleagues (Young et al., 2001a, b) which identifies, isolates and characterises MSC within the connective tissue of various organs including skeletal muscle. These MSC maintain self renewal ability with the potential to give rise to different tissues of mesenchymal origin including bone, cartilage, adipose, connective tissue, muscle and tendon. A recent paper shows that 
lineage uncommitted pluripotent stem cells that reside in the connective tissue compartment of adult skeletal muscle can also give rise to neuronal cells in culture (Romero-Ramos et al., 2002). These cells may have been derived originally from marrow MSC during embryogenesis, or they may represent a separate class of MSC: little information is available on this aspect.

Based on observation of de novo formation of muscle myotubes within the interstitial spaces, Tamaki et al (2002) identified progenitor cells within these interstitial spaces of murine skeletal muscle (Tamaki et al. 2002a,b). These cells were found to be CD34+, CD45- and a high proportion was Sca1+ indicating a stem cell population. Cloned cultures (assumed to be derived from these interstitial cells) could be induced into the adipogenic, endothelial and myogenic lineages. The potential of these cultured cells to participate in skeletal muscle growth and repair was highlighted by their ability to form both vascular endothelial cells and muscle fibres after transplantation into skeletal muscle.

\section{Dermal cells}

It has been long recognized that cells from the dermis can contribute to muscle fibre formation when cocultured with myoblasts in vitro (Breton et al., 1995; Chaudhari et al., 1989; Wise et al., 1996) or when directly injected into skeletal muscle in vivo (Gibson et al., 1995; Relvas et al., 1997). This conversion seems to be mediated by a soluble factor as a small population $(10 \%)$ of dermal cells converts to the myogenic lineage when exposed to myoblast conditioned culture media. The lectin galectin- 1 is secreted by muscle cells in vitro as they enter the terminal differentiation phase of the myogenic process (Cooper and Barondes, 1990; Harrison and Wilson, 1992) and galectin-1 has been shown to convert dermal fibroblasts to the myogenic lineage (Goldring et al., 2000, 2002a,b). In explanted dermis cultures, galectin- 1 converts $30 \%$ of cells to the myogenic lineage. Some clonal cultures show complete conversion suggesting that a subset of cells within the dermal population show a greater propensity to convert. Does this represent a stem cell population within the dermis with myogenic capacity? In 2001, Toma et al. (2001) reported isolation of cells from the dermis which showed an impressive rate of conversion to a number of different lineages including neurons, adipocytes and smooth muscle. No mention was made of the myogenic potential of these cells.
It is not yet known whether human dermal cells convert to myoblasts in the presence of galectin-1. However, adult human skin fibroblasts can be converted to muscle and form well differentiated myotubes by over-expression of the skeletal muscle specific transcription factor MyoD (Lattanzi et al., 1998), a process known as forced myogenesis. High efficiency (up to $95 \%$ ) of forced myogenesis was seen with human foetal skin fibroblasts, amniocytes, or chorionic villi cells transduced with an adenoviral MyoD-vector (Roest et al., 1999) providing valuable opportunities for pre-natal diagnosis of muscle diseases. The exact nature of the population of cells within the dermis with potent myogenic potential and whether these are also present in adult human skin remains to be elucidated.

\section{Route of application}

The vast majority of transplantation studies in skeletal muscle have been based on localized intramuscular injection of cells. Methodologies that are based on a more widespread dissemination of donor cells through the circulation have considerable advantages clinically. The intra-arterial delivery of primary myoblasts has been tested with moderate success (Neumeyer et al., 1992). Intra-arterial delivery of the muscle derived CD34+, Sca1+ PP6 cells resulted in fusion of donor cells into host myofibres (Torrente et al., 2001) and a higher level of integration was achieved if muscle was pre-injured. After intra-venous injection of SP cells in the $\mathrm{mdx}$ mouse, donor cells were found in various muscles including the quadriceps, tibialis anterior and diaphragm (Gussoni et al., 1999): however, the level of donor cell incorporation remained at a level that would not be clinically irrelevant. A major problem with such systemic delivery is removal of many donor cells by entrapment in other organs and these problems may necessitate local systemic delivery perhaps using isolated limb perfusion. For effective systemic delivery, much work also needs to be undertaken to identify targeting of donor cells to the muscle tissue and the inductive signals involved for conversion into muscle cells.

\section{Conclusions}

The final differentiated state of any cell is the result of complex interactions with soluble and extracellular 
matrix signals that are integrated by the cell. An emerging theme is that the fate and behaviour of stem cells in vivo will depend upon both intrinsic and extrinsic factors. There is no doubt that stem cells with the potential to enter the myogenic program exist in many tissues. It remains to be determined whether these stem cells are merely a novelty, how widespread they are in human tissues, and what is required to harness their potential effectively for clinical purposes.

\section{References}

Allen ND, Barton SC, Hilton K, Norris ML \& Surani MA (1994) A functional analysis of imprinting in parthenogenetic embryonic stem cells. Development 120: 1473-1482.

Asakura A, Seale P, Girgis-Gabardo A, \& Rudnicki MA (2002) Myogenic specification of side population cells in skeletal muscle. J Cell Biol 159: 123-134.

Beauchamp JR, Morgan JE, Pagel CN \& Partridge TA (1999) Dynamics of myoblast transplantation reveal a discrete minority of precursors with stem cell-like properties as the myogenic source. J Cell Biol 144: 1113-1122.

Bianco P, Riminucci M, Gronthos S \& Robey PG (2001) Bone marrow stromal stem cells: Nature, biology, and potential applications. Stem Cells 19: 180-192.

Brent L, Brooks CG, Medawar PB \& Simpson E (1976) Transplantation tolerance. Bri Med Bull 32: 101-106.

Breton M, Li Z-L, Paulin D, Harris JA, Rieger F, Pincon-Raymond M \& Garcia L (1995) Myotube driven myogenic recruitment of cells during in vitro myogenesis. Dev Dynamics 202: 126-136.

Campagnoli C, Roberts IA, Kumar S, Bennett PR, Bellantuono I \& Fisk NM (2001) Identification of mesenchymal stem/progenitor cells in human first-trimester fetal blood, liver, and bone marrow. Blood 98: 2396-2402.

Chaudhari N, R D \& Beam KG (1989) Restoration of normal function in genetically defective myotubes by spontaneous fusion with fibroblasts. Nature - Lett 341: 445-447.

Condorelli G, Borello U, De Angelis L, Latronico M, Sirbella D, Coletta M, Galli R, Balconi G, Follenzi A, Frati G, Cusella De Angelis MG, Gioglio L, Amuchastegui S, Adorini L, Naldini L, Vescovi A, Dejana E \& Cossu G (2001) Cardiomyocytes induce endothelial cells to trans-differentiate into cardiac muscle: Implications for myocardium regeneration. Proc Natl Acad Sci USA 98: 10733-10738.

Cooper DN \& Barondes SH (1990) Evidence for export of a muscle lectin from cytosol to extracellular matrix and for a novel secretory mechanism. J Cell Biol 110: 1681-1691.

Cossu G \& Mavilio F (2000) Myogenic stem cells for the therapy of primary myopathies: wishful thinking or therapeutic perspective? J Clin Invest 105: 1669-1674.

Czyz J \& Wobus A (2001) Embryonic stem cell differentiation: The role of extracellular factors. Differentiation 68: 167-174.

Erices A, Conget P \& Minguell JJ (2000) Mesenchymal progenitor cells in human umbilical cord blood. Br J Haematol 109: 235-242.

Fan Y, Beilharz MW \& Grounds MD (1996) A potential alternative strategy for myoblast transfer therapy: The use of sliced muscle grafts. Cell Transplant 5: 421-429.

Frisen J (2002) Stem cell plasticity? Neuron 35: 415-418.
Fukada S, Miyagoe-Suzuki Y, Tsukihara H, Yuasa K, Higuchi S, Ono S, Tsujikawa K, Takeda S \& Yamamoto H (2002) Muscle regeneration by reconstitution with bone marrow or fetal liver cells from green fluorescent protein-gene transgenic mice. J Cell Sci 115: 1285-1293.

Geiger H, True JM, Grimes B, Carroll EJ, Fleischman RA \& Van Zant G (2002) Analysis of the hematopoietic potential of musclederived cells in mice. Blood 100: 721-723.

Gibson AJ, Karasinski J, Relvas J, Moss J, Sherratt TG, Strong PN \& Watt DJ (1995) Dermal fibroblasts convert to a myogenic lineage in mdx mouse muscle. J Cell Sci 108: 207-214.

Goldring K, Jones GE, Sewry CA \& Watt DJ (2002a) The musclespecific marker desmin is expressed in a proportion of human dermal fibroblasts after their exposure to galectin-1. Neuromuscul Disord 12: 183-186.

Goldring K, Jones GE, Thiagarajah R \& Watt DJ (2002b) The effect of galectin-1 on the differentiation of fibroblasts and myoblasts in vitro. J Cell Sci 115: 355-366.

Goldring K, Jones GE \& Watt DJ (2000) A factor implicated in the myogenic conversion of nonmuscle cells derived from the mouse dermis. Cell Transplant 9: 519-529.

Goldring K, Partridge T \& Watt D (2002c) Muscle stem cells. J Pathol 197: 457-467.

Goodell MA, Brose K, Paradis G, Conner AS \& Mulligan RC (1996) Isolation and functional properties of murine hematopoietic stem cells that are replicating in vivo. J Exp Med 183: 1797- 1806 .

Grounds MD (1983) Skeletal muscle precursors do not arise from bone marrow cells. Cell Tiss Res 234: 713-722.

Grounds MD (1991) Towards understanding skeletal muscle regeneration. Pathology 187: 1-22.

Grounds MD, White J, Rosenthal N \& Bogoyevitch MA (2002) The role of stem cells in skeletal and cardiac muscle repair (submitted).

Gussoni E, Bennett RR, Muskiewicz KR, Meyerrose T, Nolta JA, Gilgoff I, Stein J, Chan YM, Lidov HG, Bonnemann CG, Von Moers A, Morris GE, Den Dunnen JT, Chamberlain JS, Kunkel LM \& Weinberg K (2002) Long-term persistence of donor nuclei in a Duchenne muscular dystrophy patient receiving bone marrow transplantation. J Clin Invest 110: 807-814.

Gussoni E, Soneoka Y, Strickland CD, Buzney EA, Khan MK, Flint AF, Kunkel LM \& Mulligan RC (1999) Dystrophin expression in the mdx mouse restored by stem cell transplantation. Nature 401: 390-394.

Harrison FL \& Wilson TJ (1992) The 14 kDa beta-galactoside binding lectin in myoblast and myotube cultures: localization by confocal microscopy. J Cell Sci 101 (Pt 3): 635-646.

Hodgetts SI, Beilharz MW, Scalzo T \& Grounds MD (2000) Why do cultured transplanted myoblasts die in vivo? DNA quantification shows enhanced survival of donor male myoblasts in host mice depleted of CD4+ and CD8+ or NK1.1+ cells. Cell Transplant 9: 489-502.

Iezzi S, Cossu G, Nervi C, Sartorelli V \& Puri PL (2002) Stagespecific modulation of skeletal myogenesis by inhibitors of nuclear deacetylases. Proc Natl Acad Sci USA 99: 7757-7762.

Jackson K, Mi T \& Goodell M (1999) Hematopoietic potential of stem cells isolated from murine skeletal muscle. Proc Natl Acad Sci USA 96: 14482-14486.

Jiang Y, Jahagirdar BN, Reinhardt RL, Schwartz RE, Keene CD, Ortiz-Gonzalez XR, Reyes M, Lenvik T, Lund T, Blackstad M, Du J, Aldrich S, Lisberg A, Low WC, Largaespada DA \& Verfaillie CM (2002) Pluripotency of mesenchymal stem cells derived from adult marrow. Nature 418: 41-49. 
Kehat I, Kenyagin-Karsenti D, Snir M, Segev H, Amit M, Gepstein A, Livne E, Binah O, Itskovitz-Eldor J \& Gepstein L (2001) Human embryonic stem cells can differentiate into myocytes with structural and functional properties of cardiomyocytes. J Clin Invest 108: 407-413.

Lattanzi L, Salvatori G, Coletta M, Sonnino C, Cusella De Angelis MG, Gioglio L, Murry CE, Kelly R, Ferrari G, Molinaro M, Crescenzi M, Mavilio F, \& Cossu G (1998) High efficiency myogenic conversion of human fibroblasts by adenoviral vectormediated MyoD gene transfer. An alternative strategy for ex vivo gene therapy of primary myopathies. J Clin Invest 101: 2119-2128.

Lee JY, Qu-Petersen Z, Cao B, Kimura S, Jankowski R, Cummins J, Usas A, Gates C, Robbins P, Wernig A \& Huard J (2000) Clonal isolation of muscle-derived cells capable of enhancing muscle regeneration and bone healing. J Cell Biol 150: 1085-1100.

Lewis ID \& Verfaillie CM (2000) Multi-lineage expansion potential of primitive hematopoietic progenitors: Superiority of umbilical cord blood compared to mobilized peripheral blood. Exp Hematol 28: 1087-1095.

Liechty KW, MacKenzie TC, Shaaban AF, Radu A, Moseley AM, Deans R, Marshak DR \& Flake AW (2000) Human mesenchymal stem cells engraft and demonstrate site-specific differentiation after in utero transplantation in sheep. Nat Med 6: 1282-1286.

Mann JR, Gadi I, Harbison ML, Abbondanzo SJ \& Stewart CL (1990) Androgenetic mouse embryonic stem cells are pluripotent and cause skeletal defects in chimeras: Implications for genetic imprinting. Cell 62: 251-260.

Mann JR \& Stewart CL (1991) Development to term of mouse androgenetic aggregation chimeras. Development 113: 1325-1333.

Mareschi K, Biasin E, Piacibello W, Aglietta M, Madon E \& Fagioli F (2001) Isolation of human mesenchymal stem cells: Bone marrow versus umbilical cord blood. Haematologica 86 : 1099-1100.

McKarney LA, Overall ML \& Dziadek M (1997) Myogenesis in cultures of uniparental mouse embryonic stem cells: Differing patterns of expression of myogenic regulatory factors. Int J Dev Biol 41: 485-490.

McKinney-Freeman SL, Jackson KA, Camargo FD, Ferrari G, Mavilio F \& Goodell MA (2002) Muscle-derived hematopoietic stem cells are hematopoietic in origin. Proc Natl Acad Sci USA 99: $1341-1346$.

Minasi MG, Riminucci M, De Angelis L, Borello U, Berarducci B, Innocenzi A, Caprioli A, Sirabella D, Baiocchi M, De Maria R, Boratto R, Jaffredo T, Broccoli V, Bianco P \& Cossu G (2002) The meso-angioblast: A multipotent, self-renewing cell that originates from the dorsal aorta and differentiates into most mesodermal tissues. Development 129: 2773-2783.

Mueller GM, O'Day T, Watchko JF \& Ontell M (2002) Effect of injecting primary myoblasts versus putative muscle-derived stem cells on mass and force generation in mdx mice. Hum Gene Ther 13: $1081-1090$.

Neumeyer AM, DiGregorio DM \& Brown Jr RH (1992) Arterial delivery of myoblasts to skeletal muscle. Neurology 42: 2258-2262.

Pereira RF, Halford KW, O'Hara MD, Leeper DB, Sokolov BP, Pollard MD, Bagasra O \& Prockop DJ (1995) Cultured adherent cells from marrow can serve as long-lasting precursor cells for bone, cartilage, and lung in irradiated mice. Proc Natl Acad Sci USA 92: 4857-4861.

Pittenger MF, Mackay AM, Beck SC, Jaiswal RK, Douglas R, Mosca JD, Moorman MA, Simonetti DW, Craig S \& Marshak DR
(1999) Multilineage potential of adult human mesenchymal stem cells. Science 284: 143-147.

Prelle K, Wobus AM, Krebs O, Blum WF \& Wolf E (2000) Overexpression of insulin-like growth factor-II in mouse embryonic stem cells promotes myogenic differentiation. Biochem Biophys Res Commun 277: 631-638.

Presnell S, Petersen B \& Heidaran M (2002) Stem cells in adult tissues. Semin Cell Dev Biol 13: 369.

Prockop DJ (1997) Marrow stromal cells as stem cells for nonhematopoietic tissues. Science 276: 71-74.

Qu Z, Balkir L, van Deutekom JCT, Robbins PD, Pruchnic R \& Huard J (1998) Development of approaches to improve cell survival in myoblast transfer therapy. J Cell Biol 142: 1257-1267.

Relvas JB, Aldridge H, Wells KE, Wells DJ \& Watt DJ (1997) Exogenous genes are expressed in mdx muscle fibres following the implantation of primary mouse skin cells. Basic Appl. Myology 7: $211-219$.

Reyes M, Dudek A, Jahagirdar B, Koodie L, Marker PH \& Verfaillie CM (2002) Origin of endothelial progenitors in human postnatal bone marrow. J Clin Invest 109: 337-346.

Reyes M \& Verfaillie CM (2001) Characterization of multipotent adult progenitor cells, a subpopulation of mesenchymal stem cells. Ann N Y Acad Sci 938: 231-233; discussion 233-235.

Roest PA, Bakker E, Fallaux FJ, Verellen-Dumoulin C, Murry CE \& Den Dunnen JT (1999) New possibilities for prenatal diagnosis of muscular dystrophies: Forced myogenesis with an adenoviral MyoD-vector. Lancet 353: 727-728.

Rohwedel J, Guan K, Zuschratter W, Jin S, Ahnert-Hilger G, Furst D, Fassler R \& Wobus AM (1998) Loss of betal integrin function results in a retardation of myogenic, but an acceleration of neuronal, differentiation of embryonic stem cells in vitro. Dev Biol 201: 167-184.

Rohwedel J, Maltsev V, Bober E, Arnold HH, Hescheler J \& Wobus AM (1994) Muscle cell differentiation of embryonic stem cells reflects myogenesis in vivo: Developmentally regulated expression of myogenic determination genes and functional expression of ionic currents. Dev Biol 164: 87-101.

Romero-Ramos M, Vourc'h P, Young HE, Lucas PA, Wu Y, Chivatakarn O, Zaman R, Dunkelman N, El-Kalay MA \& Chesselet MF (2002) Neuronal differentiation of stem cells isolated from adult muscle. J Neurosci Res 69: 894-907.

Rubinstein P, Dobrila L, Rosenfield RE, Adamson JW, Migliaccio G, Migliaccio AR, Taylor PE \& Stevens CE (1995) Processing and cryopreservation of placental/umbilical cord blood for unrelated bone marrow reconstitution. Proc Natl Acad Sci USA 92: 10119-10122.

Saito MD, Dennis JE, Lennon DP, Young RG \& Caplan AI (1995) Myogenic expression of mesenchymal stem cells within myotubes of mdx mice in vivo and in vitro. Tissue Engineer 1: 377-343.

Skuk D \& Tremblay JP (2000) Progress in myoblast transplantation: A potential treatment of dystrophies. Micros Res Tech 48: 213-222.

Smythe GM \& Grounds MD (2000) Exposure to tissue culture conditions can adversely affect myoblast behaviour in vivo in whole muscle grafts: Implications for myoblast transfer therapy. Cell Transplant 9: 379-393.

Smythe GM, Hodgetts SI \& Grounds MD (2000) Immunobiology and the future of myoblast transfer therapy. Mol Ther 1: 303-313.

Smythe GM, Hodgetts SI \& Grounds MD (2001) Problems and solutions in myoblast transfer therapy. J Cell Molec Med 5: $33-47$. 
Tamaki T, Akatsuka A, Ando K, Nakamura Y, Matsuzawa H, Hotta T, Roy RR \& Edgerton VR (2002a) Identification of myogenicendothelial progenitor cells in the interstitial spaces of skeletal muscle. J Cell Biol 157: 571-577.

Tamaki T, Akatsuka A, Yoshimura S, Roy RR \& Edgerton VR (2002b) New fiber formation in the interstitial spaces of rat skeletal muscle during postnatal growth. 50: 1097-1111 (submitted).

Terada N, Hamazaki T, Oka M, Hoki M, Mastalerz DM, Nakano Y, Meyer EM, Morel L, Petersen BE \& Scott EW (2002) Bone marrow cells adopt the phenotype of other cells by spontaneous cell fusion. Nature 416: 542-545.

Toma JG, Akhavan M, Fernandes KJ, Barnabe-Heider F, Sadikot A, Kaplan DR \& Miller FD (2001) Isolation of multipotent adult stem cells from the dermis of mammalian skin. Nat Cell Biol 3: $778-784$.

Torrente Y, Tremblay J-P, Pisati F, Belicchi M, Rossi B, Sironi M, Fortunato F, El Fahime M, D'Angelo MG, Caron NJ, Constantin G, Paulin D, Scarlato G, \& Bresolin N (2001) Intraarterial injection of muscle-derived CD34+Sca-1+ stem cells restores dystrophin in mdx mice. J Cell Biol 152: 335-348.

Wagers AJ, Sherwood RI, Christensen JL \& Weissman IL (2002) Little evidence for developmental plasticity of adult hematopoietic stem cells. Science 297: 2256-2259.

Wakitani S, Saito T \& Caplan AI (1995) Myogenic cells derived from rat bone marrow mesenchymal stem cells exposed to 5-azacytidine. Muscle Nerve 18: 1417-1426.
Wise CJ, Watt DJ \& Jones GE (1996) Conversion of dermal fibroblasts to a myogenic lineage is induced by a soluble factor derived from myoblasts. J Cell Biochem 61: 363-374.

Wright WE \& Shay JW (2002) Historical claims and current interpretations of replicative aging. Nat Biotechnol 20: 682-688.

Wyrsch A, Dalle Carbonare V, Jansen W, Chklovskaia E, Nissen C, Surbek D, Holzgreve W, Tichelli A \& Wodnar-Filipowicz A (1999) Umbilical cord blood from preterm human fetuses is rich in committed and primitive hematopoietic progenitors with high proliferative and self-renewal capacity. Exp Hematol 27: 1338-1345.

Ying QL, Nichols J, Evans EP \& Smith AG (2002) Changing potency by spontaneous fusion. Nature 416: 545-548.

Young HE, Duplaa C, Young TM, Floyd JA, Reeves ML, Davis KH, Mancini GJ, Eaton ME, Hill JD, Thomas K, Austin T, Edwards C, Cuzzourt J, Parikh A, Groom J, Hudson J \& Black Jr AC (2001a) Clonogenic analysis reveals reserve stem cells in postnatal mammals: I. Pluripotent mesenchymal stem cells. Anatomical Record 263: 350-360.

Young HE, Steele TA, Bray RA, Hudson J, Floyd JA, Hawkins K, Thomas K, Austin T, Edwards C, Cuzzourt J, Duenzl M, Lucas PA \& Black Jr AC (2001b) Human reserve pluripotent mesenchymal stem cells are present in the connective tissues of skeletal muscle and dermis derived from fetal, adult, and geriatric donors. Anatomical Record 264: 51-62.

Zammit P \& Beauchamp J (2001) The skeletal muscle satellite cell: Stem cell or son of stem cell? Differentiation 68: 193-204. 